\title{
Takotsubo cardiomyopathy presenting during a surgery under local anesthesia: a case report
}

\author{
Ming Yew, Yan-Syun Zeng, Wan-Jung Cheng, Li-Kai Wang, Jen-Yin Chen \\ Department of Anesthesiology, Chi Mei Medical Center, Tainan, Taiwan
}

\section{[] Background}

Takotsubo cardiomyopathy (TCM), characterized by transient left ventricular (LV) dysfunction without angiographic evidence of coronary artery lesion, mainly affects postmenopausal women and is often triggered by stressful situations ${ }^{1}$. Here we present a case of TCM, whose initial manifestations were tachycardia and pulmonary edema during a surgery under local anesthesia (LA).

\section{4) Case report}

A 68-year-old female without past medical history underwent paranasal sinus surgery under LA. Premedications (diphenhydramine $30 \mathrm{mg} \mathrm{IM}$, atropine $0.3 \mathrm{mg}$ IM and midazolam $2.5 \mathrm{mg}$ IV push) were given $0.5 \mathrm{~h}$ before surgery. Gauze packing and local infiltration of nasal cavity were done with lidocaine-epinephrine. However, sinus tachycardia with intermittent short-run VT and desaturation occurred toward the end of operation. Anesthesiologists were called for help. Supplemental $\mathrm{O}_{2}$ via facemask was given. The breath sound (BS) was diffuse rhonchi and wheezes, and several puffs of inhaled fenoterol (100 $\mu \mathrm{g} / \mathrm{puff}) \mathrm{were}$ given. Rapid sequence intubation was done in view of persistent desaturation $\left(\mathrm{SpO}_{2} 71-80 \%\right)$ and hypotension. Much pink foaming sputum and diffuse crackles in $\mathrm{BS}$ were noted, while arterial blood gas showed poor oxygenation and mild $\mathrm{CO}_{2}$ retention. IV infusion of dopamine $(11 \mu \mathrm{g} / \mathrm{kg} / \mathrm{min})$ was started for hypotension at OR. At ICU, blood level of high-sensitivity troponin I was $4563.2 \mathrm{ng} / \mathrm{L}$, 12-lead EKG showed T-wave inversion in leads V1-6, and chest X-ray revealed bilateral pulmonary edema. Echocardiography demonstrated an ejection fraction of $50 \%$ with anteroseptal LV hypokinesia. Coronary angiogram showed a myocardial bridge of LAD without other coronary artery lesion. TCM was diagnosed. The patient was treated with isosorbide, furosemide and aspirin. She was extubated 3 days later and was discharged 6 more days later without sequelae. Echocardiography 1 month later showed no regional wall abnormality of LV.
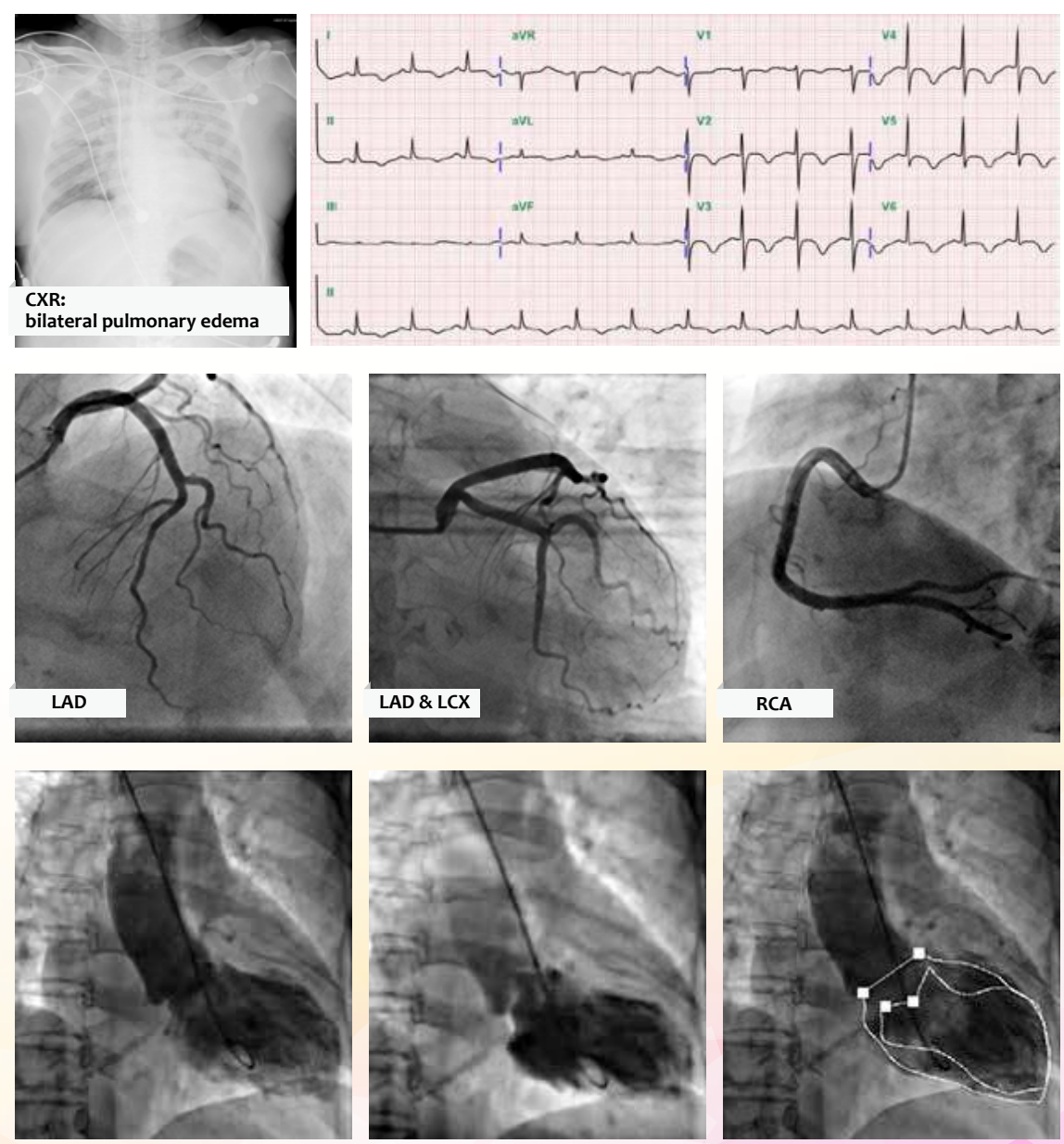

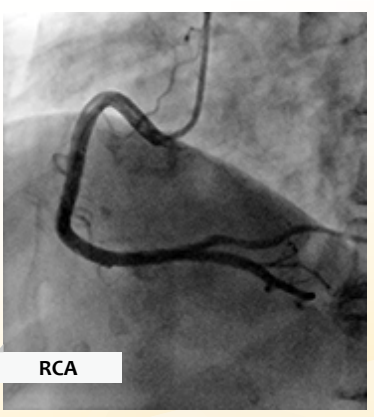

\section{Discussion}

Catecholamine excess has been postulated as a pathogenic mechanism for TCM. Exposure to epinephrine, pain on LA injections and emotional stress in this patient may have induced vasoconstriction or vasospasm and subsequent myocardial stunning that caused $\mathrm{TCM}^{2}$.

\section{प] Learning point}

Since stress is a possible trigger of TCM, emotional stress and pain should be avoided by adequate sedation, reassurance and analgesia in the perioperative setting.

\section{प) References}

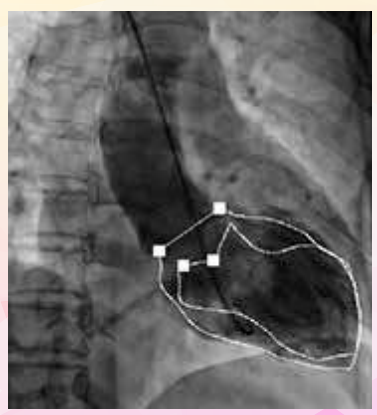

1. Gianni M, Dentali F, Grandi AM, et al. Apical ballooning syndrome or takotsubo cardiomyopathy: a systemic review. Eur Heart J. 2006;27:1523-9.

2. Wittstein IS, Theimann DR, Lima JA, et al. Neurohumoral features of myocardial stunning due to sudden emotional stress. N Engl J Med. 2005; 352:539-48. 